\title{
GESTÃO DE RESÍDUOS NAS INSTALAÇÕES DA AGÊNCIA PAULISTA DE TECNOLOGIA DOS AGRONEGÓCIOS (APTA - PÓLO CENTRO SUL, PIRACICABA - SP)
}

\section{WASTE MANAGEMENT IN THE PLANT OF THE PAULISTA AGRIBUSINESS TECHNOLOGY AGENCY (APTA - CENTER SOUTH POLE, PIRACICABA - SP)}

\section{Nadia Valério Possignolo'; Glauco Arnold Tavares ${ }^{1}$; Edna Ivani Bertoncini ${ }^{2}$; André Cesar Vitti ${ }^{2}$; Fábio Luis Ferreira Dias $^{2}$; José Albertino Bendassolli ${ }^{1}$}

${ }^{1}$ Centro de Energia Nuclear na Agricultura - CENA/USP, Faculdade de Americana FAM. E-mail nadia_valerio@yahoo.com.br; gtavares@cena.usp.br; jab@cena.usp.br ${ }^{2}$ Agência Paulista de Tecnologia dos Agronegócios, APTA, Polos Centro Sul, Brasil.

E-mail ebertoncini@apta.sp.gov.br; acvitti@apta.sp.gov.br; dias@iac.sp.gov.br

\begin{abstract}
RESUMO
Este estudo teve como objetivo estabelecer práticas de gestão de resíduos gerados na APTA Pólo Centro-Sul. O inventário do passivo relacionado com os agrotóxicos resultou em uma lista com 104 ingredientes ativos, dentre os quais 16 com restrições legais, armazenados em condições inadequadas. No inventário do ativo relacionado com resíduos químicos foi observada a geração de soluções contendo metais, tais como o cromo e cobre. A técnica de precipitação química conferiu ao tratamento uma eficiência superior a $99,9 \%$, permitindo atender o limite estabelecido pela legislação. Os resultados alcançados foram promissores e demonstraram um ganho ambiental considerável.

Palavras-chave: Resíduos Perigosos. Gestão e Gerenciamento de Resíduos Sólidos. Tratamento de Resíduos Sólidos.
\end{abstract}

\begin{abstract}
This study aimed to establish practices on management of wastes generated in APTA Center South Pole. The passive inventory related to pesticides resulted in a list of 104 active ingredients, among which 16 with law restrictions, stored in inappropriate conditions. In the active inventory related to chemical wastes the generation of solutions containing metals, such as chromium and copper was observed. Due to the chemical precipitation technique, the treatment achieved an efficiency greater than $99,9 \%$, which allowed it to meet the limits established by the environmental legislation. The achievements were promising and demonstrated considerable environmental gain.
\end{abstract}

Keywords: Dangerous wastes. Solid wastes management. Solid wastes treatment. 


\section{INTRODUÇÃO}

No cenário atual, discute-se muito a importância de se minimizar o volume dos resíduos gerados, especialmente aqueles que apresentam características de periculosidade e toxicidade. Entretanto, considerando os altos investimentos a serem angariados para tal prática, faz com que certos geradores encontrem outras formas de dispor seus resíduos sem pagar muito por isso. Infelizmente, quem paga o custo dessa escolha é a sociedade e, principalmente, o meio ambiente.

De forma a contribuir na mudança desse cenário, as universidades assumem uma responsabilidade especial para com a sociedade, pois elas educam os futuros tomadores de decisão, exercendo assim uma função multiplicadora. É chegado o momento das universidades, e em especial das instituições de ensino, pesquisa e extensão que manipulam e geram resíduos perigosos, implementarem seus Programas de Gerenciamento de Resíduos Químicos (PGRQs), o que vem sendo realizado em diversas instituições localizadas no estado de São Paulo (DEMAMAN et al., 2004; GERBASE et al., 2006; IMBROISI et al., 2006).

Nesse contexto, tendo como principal referência o PGRQ implementado no Centro de Energia Nuclear na Agricultura (CENA/USP), o objetivo do trabalho foi estabelecer a gestão dos resíduos gerados na APTA Pólo Centro Sul (APTA-PCS), com ênfase aos resíduos químicos laboratoriais e fitossanitários. Desse modo, a proposta contemplou: (1) o diagnóstico dos ativos e passivos ambientais; (2) a elaboração de protocolos de tratamento dos resíduos gerados em procedimentos analíticos realizados em amostras de solo e plantas.

\section{MATERIAL E MÉTODOS}

\section{1 Área de Estudo}

A Agência Paulista de Tecnologia dos Agronegócios é vinculada à Secretaria de Agricultura e Abastecimento do Estado de São Paulo e tem a missão de coordenar e gerenciar as atividades de ciência e tecnologia voltadas para o agronegócio. O Pólo Centro Sul, sediado em Piracicaba-SP, na rodovia SP 127, $\mathrm{km} \mathrm{30,} \mathrm{atende} \mathrm{a} 40$ municípios circunvizinhos e desenvolve pesquisas nas seguintes áreas: cana para alimentação animal; controle de matoespécies em cana; nutrição e adubação de cana; produção orgânica; e com merecido destaque em pesquisas de melhoramento genético para obtenção de cultivares de cana-de-açúcar mais produtivos, com maior teor de sacarose, resistentes às doenças e indicados para colheita mecânica (APTA, 2011).

\subsection{Materiais}

Os equipamentos necessários ao desenvolvimento da pesquisa, além das vidrarias convencionais de laboratório (balões volumétricos, provetas, pipetas, béqueres, erlenmeyers, entre outras), foram: espectrofotômetro de Absorção Atômica Perkin Elmer, modelo 3110; fotômetro de chama Digimed DM-61; agitador magnético Fisaton, modelo 750A; centrífuga IEC Centra GP8; balança eletrônica digital And, modelo ER-182A (escala 0,0001g); balança Balmak, modelo MP-2 Classe III; medidor de pH Testo 230; medidor de condutividade Testo 240; cronômetro digital Cronobio SW-2018 e equipamentos de segurança individual (bota, luva, óculos, macacão Tyvek, jaleco, respirador semi facial 3M com cartucho químico para vapores orgânicos) e coletiva (capela especial para manuseio e processamento dos materiais perigosos).

Os reagentes foram utilizados com pureza adequada para a realização do trabalho (grau analítico), com exceção do hidróxido de sódio perolado comercial obtido junto à Chemco. Os reagentes sulfato de cobre e dicromato de potássio foram adquiridos da Merck. Os ácidos sulfúrico e clorídrico foram obtidos junto à Chemco e o ácido nítrico da Nuclear. Os reagentes metabissulfito de sódio, sulfeto de hidrogênio monohidratado e peróxido de hidrogênio foram adquiridos da 
Dinâmica, Vetec e Synth, respectivamente. As soluções residuais contendo cromo e cobre foram coletadas junto aos laboratórios da APTA-PCS, assim como a água desionizada.

\subsection{Métodos}

\subsubsection{Propostas para o gerenciamento de resíduos na APTA-PCS}

O PGRQ deve assegurar que todos os resíduos sejam gerenciados de forma apropriada e segura, desde a geração até a destinação final. Assim, para a implementação e operação do PGRQ da APTA-PCS foram definidos os seguintes itens:

- Estrutura e Responsabilidade: o fornecimento de toda a estrutura necessária para a gestão dos resíduos foi competência do diretor da instituição e a responsabilidade por cada atividade componente do PGRQ atribuída aos pesquisadores geradores dos resíduos;

- Treinamento e Competência: o treinamento para pesquisadores e estagiários fundamentouse na disseminação de informações relativas às características e aos riscos inerentes ao trato de cada tipo de resíduo, à orientação quanto à execução das tarefas de coleta, transporte e armazenamento, e à utilização adequada de equipamentos de proteção individual (EPI) e coletiva (EPC), necessários para a condução segura dos experimentos. Essas informações foram compiladas em um Manual em função das análises realizadas nos laboratórios. Para procedimentos de emergência, em caso de contato ou contaminação com o resíduo, tanto individual quanto ambiental, foram utilizadas fichas MSDS (Material Safety Data Sheets) e FISPQ (Ficha de Informação de Segurança do Produto Químico);

- Segregação e Acondicionamento: Os critérios de segregação utilizados referem-se à separação dos resíduos que possam gerar condições perigosas quando combinados, evitando a mistura de resíduos de classes distintas de periculosidade ou incompatíveis entre si. Assim, a partir do diagnóstico do ativo, foram disponibilizados recipientes com diferentes volumes, para armazenamento provisório de resíduos líquidos e sólidos (metais precipitados, por exemplo) que foram encaminhados para destinação final que envolveu o tratamento, reaproveitamento, reciclagem ou disposição final em Aterro Industrial Classe I. Para isso, recipientes com volumes de $5 \mathrm{~L}, 30 \mathrm{~L}$ e $50 \mathrm{~L}$ foram comumente utilizados. Estabeleceu-se, também, que esses recipientes seriam identificados fazendo-se uso de um rótulo padrão contendo informações importantes para o correto gerenciamento, como concentração dos constituintes do resíduo, quantidade armazenada, gerador responsável e data da geração (Figura 1).

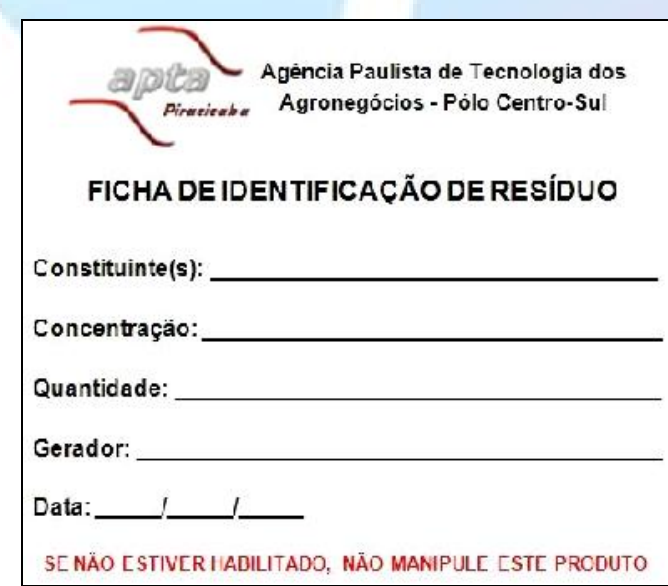

Figura 1. Rótulo para identificação dos resíduos químicos gerados na APTA-PCS 
- Pré-tratamento: Em muitos casos, os resíduos requerem algum tipo de pré-tratamento antes do seu próximo encaminhamento (destinação ou disposição final). Em relação aos resíduos químicos laboratoriais, foram implementados como pré-tratamento, processos físicos que englobam a filtração, para resíduos que contenham sólidos finos, e separação gravitacional, para sólidos de maior granulometria;

- Técnicas de tratamento: Técnicas simples como a precipitação química e neutralização ácido/base mostraram-se úteis para o tratamento dos resíduos identificados. É importante ressaltar que essas técnicas, na maioria das vezes, são utilizadas em sequência para o tratamento do mesmo resíduo;

- Destinação final: Para a destinação final dos resíduos fitossanitários, a técnica escolhida foi a incineração e, para os resíduos químicos laboratoriais foram empregadas técnicas como a precipitação química, a neutralização ácido/base, a oxirredução e a secagem sob irradiação solar;

- Disposição final: Para os rejeitos químicos não passíveis de reaproveitamento ou reciclagem, nesse caso, rejeitos da precipitação de metais, o encaminhamento para Aterro Industrial Classe I foi a alternativa mais viável encontrada.

\subsubsection{Resíduos fitossanitários}

O inventário dos agrotóxicos armazenados no depósito da APTA-PCS fundamentou-se em dois procedimentos investigativos: (1) diagnóstico qualitativo, baseado no levantamento de informações relacionadas aos agrotóxicos, no qual, para cada ingrediente ativo (IA), foram observados, nos próprios rótulos dos produtos ou então na literatura específica, parâmetros como Grupo Químico (GQ), Classe Toxicológica (CT) e Periculosidade Ambiental (PA); (2) diagnóstico quantitativo baseado na tabulação desses dados, na qual, a partir da concentração de cada IA e do respectivo volume do produto, obteve-se a quantidade $(\mathrm{kg})$ de cada IA armazenado no depósito.

De posse dessas informações, foram tomadas as decisões a respeito do reaproveitamento e destinação final dos produtos. Os agrotóxicos que apresentaram características que impossibilitavam a sua utilização foram encaminhados para a incineração. Optou-se por essa via de destinação final, pois de acordo com a resolução $n^{\circ} 264$ do Conselho Nacional de Meio Ambiente (CONAMA), é proibida a destinação via co-processamento desses resíduos (BRASIL, 1999). Os recipientes encaminhados para a incineração foram identificados através de um rótulo padrão, em termos do nome comercial dos produtos e volume, o qual designava o material armazenado como "Resíduo Perigoso".

Os agrotóxicos que apresentaram características que possibilitavam a sua utilização foram encaminhados para as instalações de um novo depósito, planejado somente para o armazenamento de produtos utilizados em rotina na APTA-PCS.

\subsubsection{Soluções residuais contendo cromo}

Para que ocorra a remoção do cromo hexavalente [Cr (VI)], foi necessária a redução do mesmo para cromo trivalente [Cr (III)] em meio ácido ( $\mathrm{pH} 2,5)$, obtida mediante a dosagem de uma substância redutora (bissulfito ou metabissulfito de sódio). No processo de oxirredução, deve-se adicionar o agente redutor até que a coloração do resíduo se torne verde escura. A remoção do $\mathrm{Cr}$ (III) foi possível através da precipitação química utilizando hidróxido de sódio, por exemplo, para elevar o pH até 10. A reação de oxirredução se dá mediante a dosagem de metabissulfito de sódio $\left(\mathrm{Na}_{2} \mathrm{~S}_{2} \mathrm{O}_{5}\right)$ de acordo com a Equação 1 .

$$
2 \mathrm{Cr}_{2} \mathrm{O}_{7}{ }^{2-}+3 \mathrm{~S}_{2} \mathrm{O}_{5}{ }^{2-}+10 \mathrm{H}^{+} \rightarrow 4 \mathrm{Cr}^{+3}+6 \mathrm{SO}_{4}{ }^{2-}+5 \mathrm{H}_{2} \mathrm{O}
$$


Para verificar a aplicabilidade da metodologia (GIOVANNINI, 2008), o procedimento de redução foi realizado no tratamento das soluções residuais geradas nos laboratórios da APTA-PCS. Desta forma foi avaliada a influência do pH na etapa de precipitação do hidróxido de cromo.

Assim, foram separadas amostras do resíduo para análise da concentração total de cromo presente no resíduo e do sobrenadante objetivando a comparação com a concentração de descarte estabelecida na Resolução CONAMA 357/05 (BRASIL, 2005). Para a quantificação do cromo nas amostras e no branco analítico, por espectrometria de absorção atômica, foi preparada uma curva de referência com concentrações conhecidas de cromo $\left(0 ; 0,5 ; 1 ; 2 ; 3 ; 4\right.$ e $\left.5 \mathrm{mg} \mathrm{L}^{-1}\right)$.

\subsubsection{Soluções residuais contendo cobre}

Nos testes iniciais para estabelecer um método de tratamento para o resíduo gerado, considerou-se a possibilidade de ressolubilização do cobre precipitado na forma de óxido $\left(\mathrm{Cu}_{2} \mathrm{O}\right)$, ao longo do tempo de armazenamento. Mediante o exposto, duas amostras representativas do volume estocado foram preparadas para a determinação da concentração de cobre solúvel no resíduo. Para compor a primeira amostra, todo o resíduo gerado foi homogeneizado e, após a precipitação do $\mathrm{Cu}_{2} \mathrm{O}$, retirou-se uma alíquota do sobrenadante. Já para a segunda amostra, no momento da geração do resíduo, o mesmo foi filtrado sendo armazenado no galão somente o sobrenadante. O objetivo na diferenciação das amostras foi avaliar uma possível ressolubilização do cobre. Se isso ocorresse, e se a ressolubilização acontecesse de forma acentuada, o gerenciamento desse resíduo poderia ser voltado somente para a sua filtração no instante da geração, removendo o precipitado, neutralizando o sobrenadante e efetuando o seu descarte, desde que a concentração de cobre estivesse de acordo com o limite para descarte.

Para a determinação da concentração de cobre nas amostras preservadas em ácido nítrico ( $\mathrm{pH} 2)$, foi preparada uma curva de referência com concentrações conhecidas de cobre $\left(0 ; 0,25 ; 0,5 ; 1 ; 2 \mathrm{mg} \mathrm{L}^{-1}\right.$ de $\left.\mathrm{Cu}\right)$ e foram adotadas como condições analíticas, chama aracetileno e comprimento de onda de 324,7 $\mathrm{nm}$ em espectrofotômetro de absorção atômica Perkin Elmer Modelo 3110.

A remoção do cobre foi avaliada através da sua reação estequiométrica com o sulfeto de sódio $\left(\mathrm{Na}_{2} \mathrm{~S}\right)$ em solução, preparada na concentração de $80 \mathrm{~g} \mathrm{~L}^{-1}$ (Equação 2). $\mathrm{O}$ fator determinante para a escolha de remover o cobre na forma de sulfeto foi o seu baixo produto de solubilidade $\left(9,0 \times 10^{-36}\right)$, o que teoricamente apresenta os melhores resultados em termos de remoção do cobre.

$$
\mathrm{CuSO}_{4}+\mathrm{Na}_{2} \mathrm{~S} \rightarrow \mathrm{CuS}(\mathrm{s})+\mathrm{Na}_{2} \mathrm{SO}_{4}
$$

Nos testes empregando o $\mathrm{Na}_{2} \mathrm{~S}$, utilizou-se também peróxido de hidrogênio $\left(\mathrm{H}_{2} \mathrm{O}_{2}\right)$ para oxidar o sulfeto em excesso (AFONSO et al., 2003). A proporção estequiométrica adicionada entre $\mathrm{H}_{2} \mathrm{O}_{2}$ e $\mathrm{Na}_{2} \mathrm{~S}$ foi de 4:1 (m/v) (Equação 3).

$$
4 \mathrm{H}_{2} \mathrm{O}_{2(\mathrm{l})}+\mathrm{Na}_{2} \mathrm{~S}_{(\mathrm{aq})} \rightarrow 4 \mathrm{H}_{2} \mathrm{O}_{(\mathrm{l})}+2 \mathrm{Na}^{+}{ }_{(\mathrm{aq})}+\mathrm{SO}_{4}{ }^{2} \text { (aq) }
$$

Em relação ao gerenciamento do resíduo sólido gerado após a etapa de precipitação, foi proposta a realização de testes para secagem desse material sob irradiação solar, o que deveria ser executado em local protegido da chuva. Como havia na APTA uma Casa de Vegetação (estufa experimental) com espaço ocioso, optou-se por dispor o resíduo em bandejas plásticas, alocadas no interior dessa Casa de Vegetação, revolvendo-o a cada 2 dias. 


\section{RESULTADOS E DISCUSSÃO}

\subsection{Gerenciamento de Resíduos Laboratoriais}

A APTA-PCS possui somente dois fluxos de resíduos químicos laboratoriais: soluções que apresentam acidez ou alcalinidade elevadas e soluções com metais pesados (cobre e cromo). Para o gerenciamento desses resíduos foram propostas técnicas como a neutralização ácido/base, a precipitação química, a oxirredução, a secagem do resíduo sob irradiação solar e a incineração. Na Tabela 1 são apresentadas as propostas de tratamento para os resíduos gerados nos laboratórios da APTA-PCS. É possível observar que a neutralização ácido/base esteve presente em todas as propostas. Essa técnica é o modo mais eficiente e rápido para gerenciar soluções ácidas e alcalinas que não contenham metais pesados (AUBURN, 2010). Para facilitar esse processo, foi disponibilizada uma bombona de $50 \mathrm{~L}$ para descarte de resíduos ácido ou alcalinos (até $1 \mathrm{~mol} \mathrm{~L}^{-1}$ ). Ao completar $90 \%$ desse volume, o resíduo final foi neutralizado ( $\mathrm{pH}$ entre 5 e 9), seguindo o estabelecido pelo CONAMA (BRASIL, 2011). Vale lembrar que na neutralização dos volumes tratados lançou-se mão de várias possibilidades de reaproveitamento de resíduos ácidos ou alcalinos e de reagentes químicos vencidos, que devem ser estimuladas, por serem econômica e ambientalmente favoráveis Reforça-se ainda que, embora em laboratórios deva-se priorizar a utilização de recipientes de volume reduzido (até $5 \mathrm{~L}$ de capacidade) para facilitar as condições de manuseio e minimizar riscos de acidentes, em alguns casos particulares, permite-se utilizar recipientes maiores, entre 20 e $50 \mathrm{~L}$ de capacidade, desde que ferramentas facilitadoras como carrinhos de transporte apropriados e bombas manuais de transferência sejam disponibilizadas.

Para o gerenciamento dos resíduos sólidos na etapa de separação das fases sólida e líquida o procedimento adotado foi simplesmente a retirada do sobrenadante por sifonação e adição do material precipitado em bandejas plásticas para secagem em Casa de Vegetação. Esse procedimento se mostrou muito eficiente em termos ambientais e operacionais, pois evitou uma utilização expressiva de papéis de filtro, considerando a alta densidade do material precipitado, ao mesmo tempo, em que evitou o desperdício de energia para secagem desses materiais em estufas ventiladas. Ao final de uma semana, os resíduos contendo ligas de Raney e Devarda estavam completamente secos, sendo armazenados em recipientes apropriados, aguardando a disposição final (envio para Aterro Industrial Classe I).

A precipitação química foi aplicada ao tratamento dos resíduos contendo cromo e cobre (Tabela 1), com o intuito de torná-los pouco solúveis, transformando-os em compostos com menor periculosidade e toxicidade. Outro aspecto de fundamental importância esteve relacionado com a acentuada redução no volume de resíduos sólidos (material precipitado seco) a ser encaminhado para disposição final e também com a alta eficiência de remoção desses metais, fazendo com que os limites para descarte, estabelecidos pela legislação, fossem atendidos. Vale ressaltar ainda que em ambos os casos, a reação tornou-se completa em um tempo relativamente curto ( $24 \mathrm{~h}$ até a completa decantação dos metais), sendo aplicável ao tratamento de grandes volumes de resíduos. Os resíduos sólidos resultantes dos tratamentos foram acondicionados em frascos plásticos, para posterior envio para disposição final (Aterro Industrial Classe I).

\subsection{Tratamento de Soluções Residuais Contendo Cromo}

A partir das análises realizadas, foi determinado que a concentração inicial de cromo total, no resíduo contendo dicromato de potássio foi de $2.088,9 \mathrm{mg} \mathrm{L}^{-1} \mathrm{de} \mathrm{Cr}$ total, valor muito acima do que a legislação permite para descarte. Após o tratamento desse resíduo, a concentração final de cromo no sobrenadante foi reduzida para $0,25 \mathrm{mg} \mathrm{L}^{-1}$, conferindo ao tratamento uma eficiência superior a 99,9\% e atendendo a legislação, que determina a concentração final de cromo total em $0,5 \mathrm{mg} \mathrm{L}^{-1}$ (BRASIL, 2005). 
Um ponto crítico que envolve o método de tratamento é o momento da redução do Cr (VI), pois se deve adicionar o bissulfito ou o metabissulfito de sódio até que a coloração do resíduo se torne verde escura. Quando o $\mathrm{Cr}$ (VI) não é totalmente reduzido, no momento da precipitação persiste a coloração levemente amarelada no sobrenadante, característica da presença deste metal em sua forma mais oxidada. É importante mencionar que essa avaliação inicial foi qualitativa, visto que essa constatação foi realizada através de análise visual.

Quando, após a precipitação, o sobrenadante apresentar essa coloração, não pode ser descartado, sendo necessário então repetir toda a operação, ou seja, diminuir o pH da solução para 2,5, reduzir o $\mathrm{Cr}$ (VI) remanescente e elevar o pH para 10. Essa condição foi testada na prática, sendo que após a segunda reação de redução do $\mathrm{Cr}$ (VI) remanescente a comparação visual permitiu concluir que todo o metal passou para forma trivalente. Vale salientar que, como a concentração inicial de Cr (VI) nessa situação é muito menor que no início do tratamento, a coloração do resíduo após a elevação do pH não será mais verde escura, e sim verde clara ou azul clara.

Tabela 1 - Alternativas de tratamento dos resíduos gerados nas análises realizadas nos laboratórios da APTA-PCS.

\begin{tabular}{|c|c|c|}
\hline Análises & Resíduos Gerados & $\begin{array}{c}\text { Protocolo de Tratamento dos } \\
\text { Resíduos }\end{array}$ \\
\hline $\begin{array}{c}\text { Determinações de } \\
\text { N-Total, N-Nítrico + } \\
\text { N-Amoniacal em } \\
\text { Solos e Resíduos } \\
\text { Orgânicos Sólidos }\end{array}$ & $\begin{array}{l}\text { - Resíduo alcalino com precipitado de } \\
\text { liga de Raney ou Devarda gerado } \\
\text { após o término da destilação. } \\
\text { - Resíduo neutro gerado após o } \\
\text { término da titulação. }\end{array}$ & $\begin{array}{l}\text { - Colocar o precipitado em bandejas } \\
\text { plásticas e secar em Casa de } \\
\text { Vegetação. Armazenar o resíduo } \\
\text { seco em recipiente apropriado para } \\
\text { envio a aterro industrial. } \\
\text { Neutralizar o resíduo alcalino } \\
\text { (pH entre 5-9) e descartar na pia. } \\
\text { - Descartar diretamente na pia. }\end{array}$ \\
\hline $\begin{array}{l}\text { Determinação de } \\
\text { Carbono em Solos }\end{array}$ & $\begin{array}{l}\text { - Resíduo ácido contendo } \mathrm{K}_{2} \mathrm{Cr}_{2} \mathrm{O}_{7} \\
\text { gerado após a titulação da amostra. }\end{array}$ & $\begin{array}{l}\text { - Adicionar } \mathrm{Na}_{2} \mathrm{~S}_{2} \mathrm{O}_{5} \text { ou } \mathrm{NaHSO}_{3} \text { até } \\
\text { o resíduo adquirir coloração verde } \\
\text { escura. Elevar o pH até 10, } \\
\text { adicionando } \mathrm{NaOH} 18 \text { mol } \mathrm{L}^{-1} \text {. } \\
\text { Aguardar a precipitação. Colocar o } \\
\text { precipitado em bandejas plásticas e } \\
\text { secar em Casa de Vegetação. } \\
\text { Armazenar o resíduo seco em } \\
\text { recipiente apropriado para envio a } \\
\text { aterro industrial. Neutralizar o } \\
\text { sobrenadante (pH entre 5-9) e } \\
\text { descartar na pia. }\end{array}$ \\
\hline Respirometria & - Resíduo contendo $\mathrm{NaOH} 0,5 \mathrm{~mol} \mathrm{~L}^{-1}$ & $\begin{array}{l}\text { - Descartar o resíduo na Bombona de } \\
\text { Mistura Ácida e/ou Alcalina. Ao } \\
\text { atingir } 80 \% \text { da capacidade } \\
\text { volumétrica }(50 \text { L), neutralizar } \\
\text { (pH entre 5-9) e descartar na pia. }\end{array}$ \\
\hline
\end{tabular}




\begin{tabular}{|c|c|c|}
\hline $\begin{array}{l}\text { Determinação de } \\
\text { Açúcares Totais e } \\
\text { Redutores - com o } \\
\text { equipamento } \\
\text { REDUTEC }\end{array}$ & - Resíduo sólido contendo $\mathrm{Cu}_{2} \mathrm{O}$ & $\begin{array}{l}\text { - Adicionar solução de } \mathrm{Na}_{2} \mathrm{~S} \text {. } \\
\text { Aguardar a completa precipitação } \\
(24 \mathrm{~h}) \text {, separar o sobrenadante } \\
\text { (sifonação) e colocar o precipitado } \\
\text { em bandejas plásticas e secar em } \\
\text { Casa de Vegetação. Armazenar o } \\
\text { resíduo seco em recipiente } \\
\text { apropriado para envio a aterro } \\
\text { industrial. Adicionar no } \\
\text { sobrenadante } \mathrm{H}_{2} \mathrm{O}_{2} \text { e descartar na } \\
\text { pia. } \\
\text { - Colocar o precipitado em bandejas } \\
\text { plásticas e secar em Casa de } \\
\text { Vegetação. Armazenar o resíduo } \\
\text { seco em recipiente apropriado para } \\
\text { envio a aterro industrial. }\end{array}$ \\
\hline
\end{tabular}

Após a avaliação visual das amostras, foi realizado um teste para verificar se a eficiência do tratamento é a mesma quando se realiza reações em $\mathrm{pH}$ de precipitação abaixo e acima do recomendado. Na Tabela 2 são apresentados os resultados desses ensaios. Pode-se observar que as eficiências nas três situações foram sempre acima de $99 \%$ e, que a eficiência do tratamento na condição ideal de $\mathrm{pH}$ foi pouco maior comparada aos outros testes. No entanto, a condição ideal foi a única situação em que a concentração de descarte do sobrenadante ficou abaixo do permitido pela legislação $\left(0,5 \mathrm{mg} \mathrm{L}^{-1}\right)$ (BRASIL, 2005). É possível observar, ainda, que quando comparada com as amostras $\mathrm{T}_{2}$ e $\mathrm{T}_{3}$, em pH diferente do recomendado, a concentração final foi menor, conferindo uma maior eficiência ao tratamento. Enquanto a falta de íons hidroxila pode prejudicar a eficiência da precipitação química, deve-se considerar também que o cromo, na presença de excesso de hidroxila ( $\mathrm{pH}$ elevado), pode formar os complexos hidroxissolúveis $\left[\mathrm{Cr}(\mathrm{OH})_{4}\right]^{-}$, promovendo a solubilização do elemento.

Tabela 2 - Influência do pH na eficiência do tratamento

\begin{tabular}{cccc}
\hline Amostra & $\begin{array}{c}\text { pH } \\
\text { precipitação }\end{array}$ & $\begin{array}{c}\text { Concentração final } \\
\left(\mathbf{m g ~ L}^{-\mathbf{1}}\right)\end{array}$ & $\begin{array}{c}\text { Eficiência } \\
(\boldsymbol{\%})\end{array}$ \\
\hline $\mathrm{T}_{1}{ }^{* * *}$ & 10,0 & 0,25 & 99,9 \\
$\mathrm{~T}_{2}{ }^{* * *}$ & 9,5 & 9,88 & 99,5 \\
$\mathrm{~T}_{3}{ }^{* * *}$ & 10,5 & 3,71 & 99,8 \\
\hline
\end{tabular}

* $\mathrm{T}_{1}$ - amostra na condição de $\mathrm{pH}$ ideal.

** $\mathrm{T}_{2}$ - amostra submetida ao $\mathrm{pH}$ abaixo do recomendado.

$* * * \mathrm{~T}_{3}-$ amostra submetida ao $\mathrm{pH}$ acima do recomendado.

Ao final do tratamento de todo volume de solução residual contendo cromo, o sobrenadante do resíduo foi separado do precipitado formado. A primeira foi neutralizada e descartada e o segundo foi levado à secagem. Como a APTA-PCS não dispõe de um filtro-prensa para a secagem do lodo, o mesmo foi colocado em formas e dispostos no interior de uma Casa de Vegetação. O tempo aproximado de secagem do lodo de $35 \mathrm{~L}$ de resíduo tratado foi de 3 meses, no verão, com revolvimento uma vez por semana. Nessas condições, embora a secagem tenha sido lenta, não houve gasto de energia e ocupação de grande espaço físico. 


\subsection{Tratamento de Soluções Residuais Contendo Cobre}

Inicialmente, foi caracterizado o resíduo e a sua geração em termos de volume. No protocolo desenvolvido na APTA-PCS, para a análise de $10 \mathrm{~mL}$ de amostra são gerados de 80 a $100 \mathrm{~mL}$ de resíduo em $\mathrm{pH}$ 6,5, totalizando anualmente $150 \mathrm{~L}$ de resíduo. As análises iniciais demonstraram que a concentração de cobre no resíduo não filtrado foi de $217,7 \mathrm{mg} \mathrm{L}^{-1}$, e que a mesma foi reduzida para 40,2 $\mathrm{mg} \mathrm{L}^{-1}$ fazendo-se uso da filtração no momento da geração. Nesse caso, demonstrou-se que o resfriamento do resíduo e a estocagem por determinado período influenciaram na ressolubilização do cobre. No entanto, apesar da filtração ter diminuído a concentração de cobre em mais de $80 \%$, esse procedimento não foi eficaz a ponto de permitir atender a legislação uma vez que a resolução CONAMA 430/11 determina que a concentração limite para descarte de cobre dissolvido é de $1 \mathrm{mg} \mathrm{L}^{-1}$ (BRASIL, 2011).

Considerando os testes empregando a solução de sulfeto de sódio, imediatamente após a adição da solução, foi observada a formação do precipitado de coloração marron-esverdeada. A solução residual foi então filtrada, e para oxidar o sulfeto a sulfato foi adicionado peróxido de hidrogênio. Ao final, a solução residual se mostrou límpida e sem precipitado. A evolução do tratamento pode ser visualizada na Figura 2.

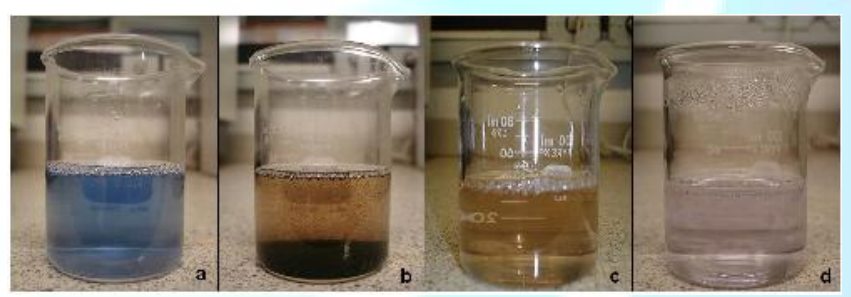

Figura 2. Etapas do tratamento do resíduo contendo cobre, sendo em a) resíduo in natura; b) precipitação do sulfeto de sódio; c) sobrenadante após tratamento; d) sobrenadante após adição do peróxido de hidrogênio

Os testes de precipitação química mostraram uma concentração final estimada em $0,46 \mathrm{mg} \mathrm{L}^{-1}$ de cobre $(\mathrm{n}=3)$, para o resíduo não filtrado. Analisando esse resultado, observa-se que a proposta de tratamento permitiu a remoção de mais de $99 \%$ do cobre, sendo que o limite estabelecido pela legislação $\left(1 \mathrm{mg} \mathrm{L}^{-1}\right)$ foi atendido (BRASIL, 2011).

Ao final do tratamento optou-se pela secagem do resíduo sólido sob irradiação solar, pois além de ser uma alternativa mais sustentável, na qual não há gasto de energia, a parte operacional não requer muitos esforços. Os precipitados de óxido cuproso e sulfeto de cobre foram dispostos em bandejas plásticas em Casa de Vegetação, e após um período de 2 semanas, o resíduo estava seco, totalizando uma massa final de aproximadamente $200 \mathrm{~g}$ resultante do tratamento de $150 \mathrm{~L}$ de resíduo.

\subsection{Gerenciamento de Resíduos Fitossanitários}

Após a execução das atividades inerentes ao inventário de passivos ambientais, foi identificado apenas um local dentro da APTA-PCS passível de ação corretiva: um depósito para armazenamento de agrotóxicos com condições precárias de acondicionamento e de segurança para esse tipo de produto (Figura 3). 


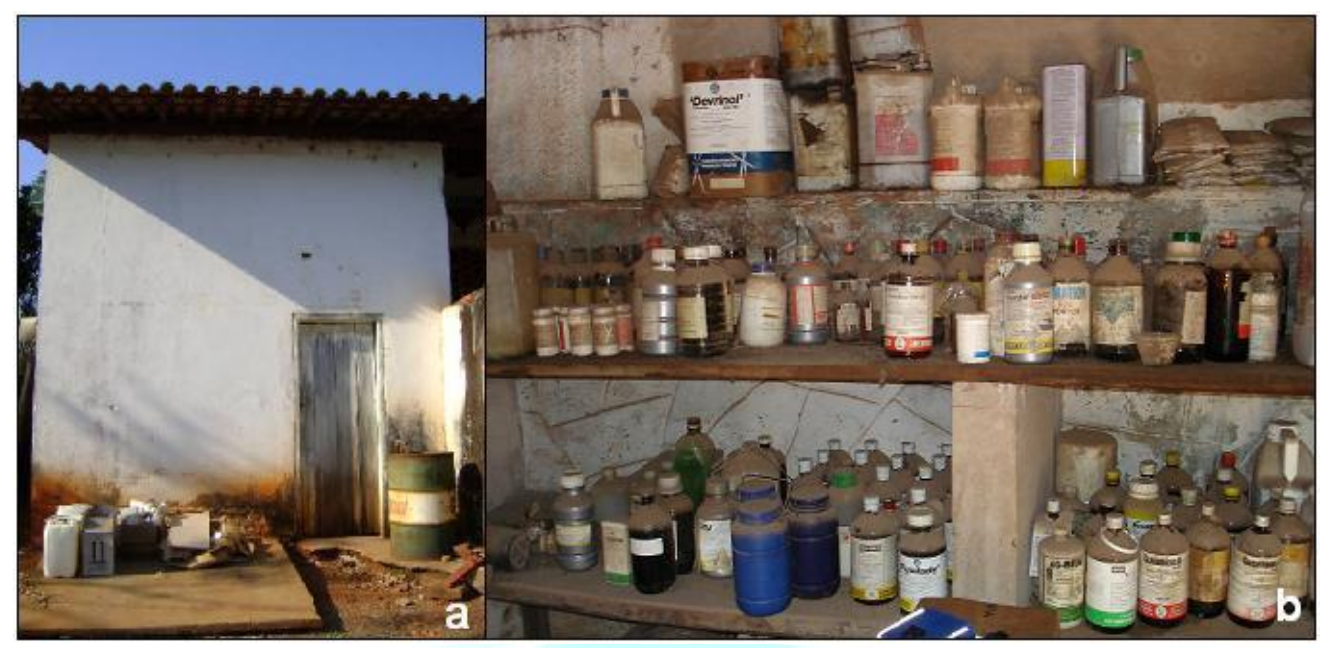

Figura 3. Passivo ambiental identificado na APTA-PCS sendo em a) entrada do depósito de agrotóxicos; b) condições precárias de acondicionamento dos produtos

As atividades de gerenciamento dos resíduos fitossanitários iniciaram-se com a organização ou estabilização do depósito, que compreendeu a limpeza de todos os recipientes, a reembalagem dos produtos vencidos, a limpeza dos derramamentos e a realocação dos produtos no depósito, procedimentos realizados com o uso de macacão, bota, luva e máscara apropriados. Aproximadamente 400 embalagens vazias foram identificadas e enviadas para a Central de Recebimento de Embalagens Vazias de Agrotóxicos de Piracicaba. O inventário resultou uma lista de 104 IAs diferentes, armazenados no depósito, sem seguir alguns dos mínimos critérios, sendo que a maioria dos produtos era representada por produtos vencidos.

Considerando o tipo de passivo e a sua ocorrência, o depósito apresentava a possibilidade de contaminação do solo e do lençol freático, devido à inexistência de um sistema de contenção de derramamentos internos, como piso liso impermeável, sob forma de bacia, e externo, como canaletas para recolhimento de produtos vazados, com caimento para uma caixa de contenção. A inexistência dessas recomendações, aliada a um eventual derramamento de um produto e condições ambientais propícias, pode favorecer processos de lixiviação e escoamento superficial do produto. Pelos produtos não estarem dispostos a céu aberto, sujeitos ao sol e a chuva, e o depósito possuir uma pavimentação, mesmo não sendo revestida de material impermeável, no entanto, trata-se de um passivo que tende a evoluir lentamente no que diz respeito à contaminação ambiental.

Além do risco ambiental associado às condições impróprias de armazenamento, o depósito também oferecia risco aos trabalhadores, pois não havia nenhum recurso para prevenção de acidentes (EPIs e EPCs), e com a existência de produtos obsoletos, vencidos e proibidos, a possibilidade de ocorrer contaminação da pele e dos olhos, ou mesmo intoxicação por inalação, era muito alta. Portanto, com base no mencionado, essa ocorrência de passivo ambiental na APTA-PCS pode ser considerada como grave.

A Agência Nacional de Vigilância Sanitária realizou no período de 2002 a 2006 a reavaliação toxicológica de diversos IAs, o que resultou em restrições ou cancelamentos no registro, devido aos seus efeitos crônicos à saúde por meio da exposição dietética e ocupacional (ANVISA, 2012). Os IAs benomil, heptacloro, monocrotofós, lindano e pentaclorofenol foram proibidos, enquanto os IAs como captana, folpete, carbendazim, clorpirifós, metamidofós, entre outros, sofreram restrições de uso. De acordo com o Projeto de Lei n 743 de agosto de 2009, em trâmite na Assembléia Legislativa de São Paulo, está previsto o banimento de 14 IAs que podem causar câncer, mutações e problemas no sistema nervoso, sendo eles: abamectina, acefato, carbofurano, cihexatina, endosulfam, forato, fosmete, glifosato, lactofem, metamidofós, paraquate, parationametílica, tiram e triclorfom (ALESP, 2009). 
Nas instalações da APTA-PCS estavam armazenados 8 desses 14 IAs, sendo 0,01 kg de abamectina; $12,93 \mathrm{~kg}$ de carbofurano; $1,15 \mathrm{~kg}$ de endosulfam; 41,73 $\mathrm{kg}$ de glifosato; 1,56 $\mathrm{kg}$ de lactofem; $1,44 \mathrm{~kg}$ de metamidofós; $0,24 \mathrm{~kg}$ de parationa-metílica e 1,96 kg de tiram. Além destas moléculas, identificou-se $0,9 \mathrm{~kg}$ de benomil; $0,94 \mathrm{~kg}$ de monocrotofós; $7,92 \mathrm{~kg}$ de captafol; $0,1 \mathrm{~kg}$ de aldrin; 1,5 L de endrin que são proibidos e, 0,48 kg de captana; 2,62 kg de carbendazim; 1,38 kg de clorpirifós que sofreram restrições ao uso. Ao final do inventário, foram listados 104 IAs diferentes.

Na Tabela 3 são apresentadas as quantidades de IA $(\mathrm{kg})$ considerando a classe dos produtos. Em relação à Classe Toxicológica e a Periculosidade Ambiental, 36\% eram medianamente tóxicos (CT III) e $25 \%$ eram muito perigosos ao meio ambiente (PA II). Vale ressaltar que aproximadamente $55 \%$ desses produtos encontravam-se fora do prazo de validade, e que produtos com a validade vencida ou armazenados em condições precárias, podem ter sua estabilidade comprometida, favorecendo a ocorrência de acidentes ou a sua ineficácia quando aplicados nas culturas.

Tabela 3 - Quantidade de IA e classe dos agrotóxicos

\begin{tabular}{ccc}
\hline Classes & Quantidade de IA (kg) & \% \\
\hline Herbicida & 345,38 & 70 \\
Inseticida & 66,81 & 14 \\
Fungicida & 40,68 & 8 \\
Fungicida/Inseticida & 20,58 & 4 \\
Fungicida/Bactericida & 10,72 & 2 \\
Outros & 6,56 & 2 \\
\hline Total & $\mathbf{4 9 0 , 7 3}$ & $\mathbf{1 0 0}$ \\
\hline
\end{tabular}

No inventário foram descriminadas também as quantidades de IA relativas aos orgânicos de síntese, no qual o grupo dos fosforados, que possuem elevada toxicidade aguda ao homem, estava em maior quantidade $(63,7 \mathrm{~kg})$, seguido pelo grupo dos carbamatos $(27,1 \mathrm{~kg})$, clorofosforados $(6,4$ $\mathrm{kg})$ e clorados $(1,5 \mathrm{~kg})$.

No depósito da APTA-PCS havia aproximadamente $360 \mathrm{~kg}$ e também $300 \mathrm{~L}$ de produtos armazenados, dos quais $193 \mathrm{~kg}$ e $215 \mathrm{~L}$ foram reaproveitados na instituição, sendo o restante encaminhado para incineração. Vale ressaltar que havia aproximadamente $108 \mathrm{~kg}$ de produtos não identificados. Os produtos de mesma classe de compatibilidade (herbicidas, inseticidas e fungicidas) encaminhados para incineração foram devidamente acondicionados em caixas de papelão ou plásticas (frascos de $1 \mathrm{~L}$ ) e também sacos plásticos (sacos de $15 \mathrm{~kg}$ ), onde o conteúdo de cada caixa ou saco foi identificado com um rótulo padrão.

Os resultados do inventário acima serviram de base para a tomada de decisão em relação ao planejamento e a construção de um novo depósito (Figura 4), seguindo as normas para armazenamento de agrotóxicos (BRASIL, 1989; ABNT, 2004). É importante mencionar que esse depósito foi planejado somente para o armazenamento de produtos para uso em rotina na APTA-PCS e que a manipulação dos mesmos deverá ser realizada necessariamente no laboratório, que foi planejado para atender as normas de manipulação. Esse depósito foi auditado por fiscais do Ministério da Agricultura em dezembro de 2010, os quais autorizaram a operação dessa instalação. 


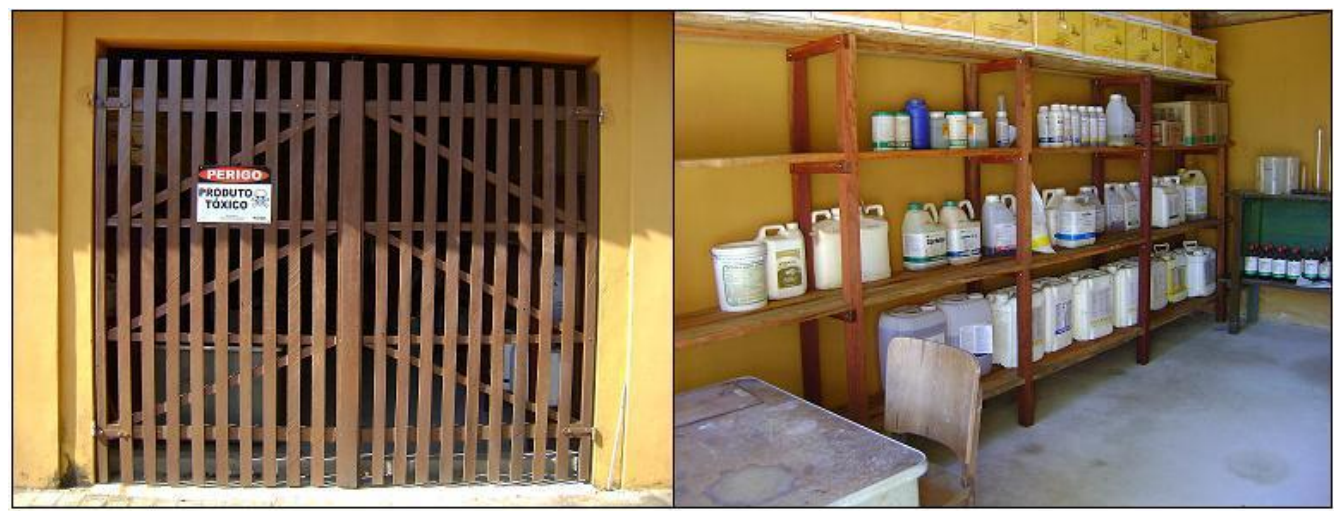

Figura 4. Depósito para o armazenamento de produtos fitossanitários utilizados em rotina na APTA-PCS

\section{CONCLUSÕES}

Os resultados alcançados na APTA-PCS são promissores e demonstram inegavelmente que o PGRQ é viável, pois além do ganho ambiental, que é considerável, alguns procedimentos envolvidos propiciaram retorno financeiro, com a redução do volume a ser disposto em aterro industrial.

Os inventários dos ativos e passivos ambientais possibilitaram conhecer as instalações da APTA-PCS em relação aos seus resíduos gerados, direcionando assim os esforços para a busca da melhor estratégia de gestão.

O descarte dos resíduos químicos de maneira incorreta nos efluentes laboratoriais pôde ser corrigido, principalmente em relação aos resíduos contendo metais. Todas as técnicas empregadas se mostraram de fácil operação, não sendo necessários grandes investimentos. Os métodos de tratamento para remoção do cromo e cobre através da precipitação química foram muito eficientes, permitindo atender o limite estabelecido pela legislação.

A continuidade dos progressos ora alcançados está relacionada à manutenção dos esforços por parte da diretoria da APTA-PCS em relação à disponibilização de recursos financeiros e humanos, os quais, de preferência, devem ser integralmente dedicados ao tratamento dos resíduos e gerenciamento das questões relacionadas e à promoção constante de atividades de conscientização e treinamento.

\section{AGRADECIMENTOS}

Os autores agradecem a FAPESP e a FUNDEPAG pelo auxilio financeiro e ao IAC e Laboratório de Química Analítica - CENA/USP pela execução das análises químicas.

\section{REFERÊNCIAS}

ABNT. Associação Brasileira de Normas Técnicas. NBR 9.843. Agrotóxicos: Armazenamento, movimentação e gerenciamento em armazéns, depósitos e laboratórios. Rio de Janeiro, 2004.

AFONSO, J.C.; NORONHA, L.A.; FELIPE, R.P.; FREIDINGER, N. Gerenciamento de resíduos laboratoriais: recuperação de elementos e preparo para descarte final. Química Nova, São Paulo, v. 26, n. 4, p. 602-611, 2003. 
ALESP. Assembléia Legislativa do Estado de São Paulo. Projeto de Lei no 743. São Paulo: ALESP, 2009.

ANVISA. Agência Nacional de Vigilância Sanitária. Programa de Análise de Resíduos de Agrotóxicos em Alimentos - PARA. Disponível em:

http://portal.anvisa.gov.br/wps/wcm/connect/3989428047457d5189a7dd3fbc4c6735/nota+tecnica++resultados+para+2008.pdf?MOD=AJPERES. Acesso em: 23 mar. 2013.

APTA. Agência Paulista de Tecnologia dos Agronegócios. Quem somos. Disponível em: http://www.aptaregional.sp.gov.br. Acesso em: 23 mar. 2013.

AUBURN. Department of Risk Management and Safety of Auburn University. Chemical waste management guide: a guide to the generation, storage and disposal of hazardous waste at Auburn University. Auburn, AL: Department of Risk Management and Safety, 2006. 92 p. Disponível em: https://cws.auburn.edu/rms/ConMan/ConMan_FileDownload.aspx?FileName=EMChemicalWaste ManagementGuide.pdf. Acesso em: 13 dez. 2010.

BRASIL. Congresso Nacional. Lei ${ }^{\circ} .7 .802$ de 11 de julho de 1989. Diário Oficial da União, Brasília, DF, 12 jul. 1989. Seção I, p. 11.459.

BRASIL. Conselho Nacional de Meio Ambiente. Resolução n ${ }^{\circ} 264$ de 26 de agosto de 1999. Diário Oficial da União, Brasília, DF, 20 mar. 2000. Seção 1, p. 80-83.

BRASIL. Conselho Nacional de Meio Ambiente. Resolução no. 357 de 15 de março de 2005. Diário Oficial da União, Brasília, DF, 18 mar. 2005. Seção 1, p. 58-63.

BRASIL. Conselho Nacional de Meio Ambiente. Resolução nº 430 de 13 de maio de 2011. Diário Oficial da União, Brasília, DF, 16 mai. 2011. Seção 1, p. 89.

DEMAMAN, A.S.; FUNK, S.; HEPP, L.U.; ADÁRIO, A.M.S.; PERGHER, S.B.C. Programa de gerenciamento de resíduos dos laboratórios de graduação da universidade regional integrada do alto Uruguai e das missões - Campus Erechim. Química Nova, São Paulo, v. 27, p.674-677, 2004.

GERBASE, A. E.; GREGÓRIO, J. R.; CALVETE, T. Gerenciamento dos resíduos da disciplina de química inorgânica II do Curso de Química da Universidade Federal do Rio Grande do Sul. Química Nova, São Paulo, v. 29, p. 397-403, 2006.

GIOVANNINI, J.G.; TAVARES, G.A.; BENDASSOLLI, J.A. Avaliação das técnicas de precipitação química e encapsulamento no tratamento e destinação conjunta de resíduos líquidos contendo cromo e vidrarias de laboratório. Química Nova, São Paulo, v. 31, n. 3, p. 676-679, 2008.

IMBROISI, D.; GUARITÁ-SANTOS, A.J.M.; BARBOSA, S.S.; SHINTAKU, S. da F.; MONTEIRO, H.J.; PONCE, G.A.E.; FURTADO, J.G. TINOCO, C.J.; MELLO, D.C. Gestão de resíduos químicos em universidades: Universidade de Brasília em foco. Química Nova, São Paulo, v. 29, n. 2, p. 404-409, 2006. 